\title{
NUMERICAL ANALYSIS OF FLOW-INDUCED VIBRATIONS IN CLOSED SIDE BRANCHES.
}

\author{
Doc. Ing. Branislav KNÍŽAT, Ing. Michal TROJÁK
}

\begin{abstract}
Vibrations occuring in closed side branches connected to a main pipe are a frequent problem during pipeline system operation. At the design stage of pipeline systems, this problem is sometimes overlooked or underestimated which can later lead to the shortening of the systems life cycle or may even cause injury. The aim of this paper is a numerical analysis of the start of selfinduced vibrations on the edge of a closed side branch. Calculation conditions and obtained results are presented within.
\end{abstract}

KEYWORDS: Closed side branch, resonance, pipeline system.

\section{INTRODUCTION}

The term „flow-induced vibrations“ denotes a phenomenon when pressure pulses occur without outer mechanical excitation. Vibration induction can be caused by fluid turbulences or by periodical vortex shedding from the trailing edge of a junction. In a case of gas as a flowing fluid, the science, which is dealing with the interactions between the gaseous stream and the solid wall, is called aeroelasticity. Besides outer aeroelastic problems (wing of an airplane), there are also inner aeroelastic problems (for example in pipeline systems). Oscillations excited in this way are mostly undesirable and dangerous phenomenon. For example, big pipeline systems are able to oscillate in the domain of low frequencies and additional cyclic loading decreases the life cycle of the whole system. A typical case can be seen in fig. 1, where a closed side branch upright on the main pipe made by a closure of a valve is pictured. Exciting force in the interface is caused by selfinduced vibrations and because the pipe is fixed elastically in constraints $\mathrm{C}$, it also begins to oscillate.



Fig. 1 - Elastically fixed closed branch

Two oscillating systems are presented: gas in a closed branch and elastically fixed pipeline system. Dangerous cases occur when the natural frequencies of a gas in the branch and a system are coincidental. Attention and research of the conditions which start self-induced vibrations as well as resonance conditions is paid in the literature. The theoretical papers [5], [7] as well as papers [2], [4], [6] describing some experiments, can be mentioned. Often, the paper [2] is cited. It introduces empirical relations obtained from an extensive database of experimental results on the basis of 
which is possible to estimate conditions of resonance in a closed branch. This paper deals with the simulation of flow in the interface between closed side-branch and main pipe where a source of exciting oscillations exists. The goal is to build a CFD model of turbulent flow able to reliably predict frequencies of exciting oscillations. Results are compared with the work [2].

\section{RESONANCE OF A GAS IN A CLOSED BRANCH} follows:

The resonance frequency of the resonator according to the fig. 1 may be expressed as

$\mathrm{f}_{\mathrm{n}}=\frac{\mathrm{n} \cdot \mathrm{c}}{4 \cdot \mathrm{L}}$

where $\mathrm{n}$ are odd integer values $(\mathrm{n}=1,3,5, \ldots), \mathrm{c}$ is an acoustic velocity in a gas, $\mathrm{L}$ is a length of the closed side branch.

The resonance frequency depends on Strouhal's number:

$\mathrm{St}=\frac{\mathrm{f}_{\mathrm{n}} \cdot \mathrm{D}}{\widetilde{\mathrm{v}}_{\mathrm{n}}}$

where $\widetilde{V}_{n}$ is the mean velocity in a main pipe, $D$ is the diameter of the main pipe.

Strouhal's number expresses geometric and flow conditions in a T junction. Strouhal's number may be expressed according [2] as follows:

$\mathrm{St}=0,399 \cdot\left(1-\frac{\mathrm{r}}{\mathrm{d}}\right)^{0,622} \cdot\left(\frac{\mathrm{d}}{\mathrm{D}}\right)^{0,316} \cdot\left(\frac{\widetilde{\mathrm{v}}_{\mathrm{n}}}{\mathrm{c}}\right)^{-0,083} \cdot\left(\frac{\rho \cdot \widetilde{\mathrm{v}}_{\mathrm{n}} \cdot \mathrm{D}}{\eta \cdot 10^{6}}\right)^{-0,06}$

where $\rho$ is the gas density, $\eta$ is the dynamic viscosity, $\mathrm{c}$ is the acoustic velocity in a gas, $r$ is the radius of an edge fillet, and $d$ is the diameter of a closed branch.

Relation (3) was estimated empirically as a regression from an extensive database of experimental data. From equations (1), (2) and (3) may be used to empirically estimated resonance frequency of a closed branch, if other parameters are known.

\section{CFD SIMULATION OF FLOW IN THE VICINITY OF A JUNCTION}

In the previous section the resonance conditions of a gas in the closed side-branch were described. Longitudinal gas oscillations in the branch are excited by a frequency of periodic vortex shedding on the trailing edge of the junction. The mechanism of the origin of exciting pulsations as well as a value of their frequency for different edge shapes is explainable only on the base of known flow pattern. Estimating the flow pattern was a task for CFD simulations. The CFD simulations were made on the basis of more simplifications for the sake of lowering computational demands as well as shortening the calculation time. All the problems above were solved as twodimensional. With respect to the fact that the main goal was an estimation of oscillation frequencies, this procedure is acceptable. Dimensions of calculated branch geometry are in fig. 2. Besides the edge radius R10 according to fig. 2 we also dealt with a radius of R20 in order to find the influence of the radius value on the stream oscillations. It was also assumed that only the junction shape (radius of the fillet, width) has an influence on the value of the exciting frequency and the length of the branch has no influence. The fluid was methane $\left(\mathrm{CH}_{4}\right)$ with a static pressure $6 \cdot 10^{6} \mathrm{~Pa}$. Acoustic speed in a gas at given conditions was estimated at $\mathrm{c}=433,5 \mathrm{~m} \cdot \mathrm{s}^{-1}$ by applying Pápay state equation. 
SCIENTIFIC PROCEEDINGS 2011, Faculty of Mechanical Engineering, STU in Bratislava Vol. 19, 2011, pp. 119-125, DOI: 10.2478/v10228-011-0020-1

\section{MESH}

To respect the complexity of the flow field (non-stationary vortex shedding) it was necessary to pay attention to the mesh quality. As a first variant a mesh suitable for application of near-wall function in the vicinity of a solid wall was used. This procedure failed (with turbulence models k- $\varepsilon$, RNG and k- $\omega$ ) and the calculated flow fields didn't agree with experimental data taken from literature (calculation didn't follow any periodic phenomena on the interface of a junction). Then two layer model were applied, where the near-wall region and the region of turbulent flow in the core were solved separately. Optimum setting of the mesh was found as follows: In the nearwall region the first cell has a size of $0,01 \mathrm{~mm}$, growth gradient 1,2 and cell count was 20 . The total cell count was approximately 120000 . Quality indicator of the mesh (skewness) had a value of 0,64 so the mesh was very good. A detail of the mesh around the radius can be seen in fig. 3 .
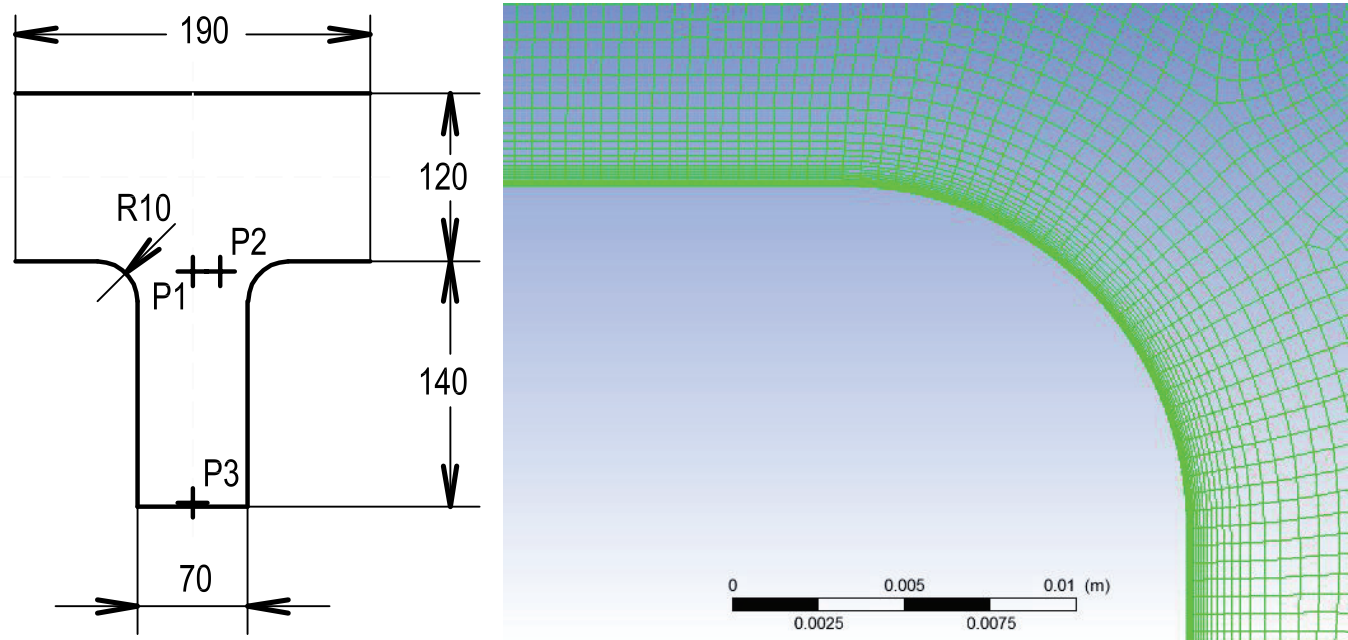

Fig. 2 - Closed branch geometry (left) and a detail of the mesh (right)

\section{MODEL DESCRIPTION}

Model of the flow is based on Reynolds equations, employing the RSM (Reynolds stress model) model for turbulence. This turbulence model is based on the fact that Reynolds stresses are possible to express in the following form:

$$
\frac{\partial \overline{u_{1}^{\prime} u_{j}^{\prime}}}{\partial t}+u_{k} \frac{\partial \overline{u_{1}^{\prime} u_{j}^{\prime}}}{\partial x_{k}}=P_{i j}-\varepsilon_{i j}+\phi_{i j}+D_{i j}
$$

where $\mathrm{P}_{\mathrm{ij}}$-turbulence production, $\varepsilon_{\mathrm{ij}}$-dissipation, $\Phi_{\mathrm{ij}}$ - redistribution term, $\mathrm{D}_{\mathrm{ij}}$-diffusion transport. 
SCIENTIFIC PROCEEDINGS 2011, Faculty of Mechanical Engineering, STU in Bratislava Vol. 19, 2011, pp. 119-125, DOI: 10.2478/v10228-011-0020-1

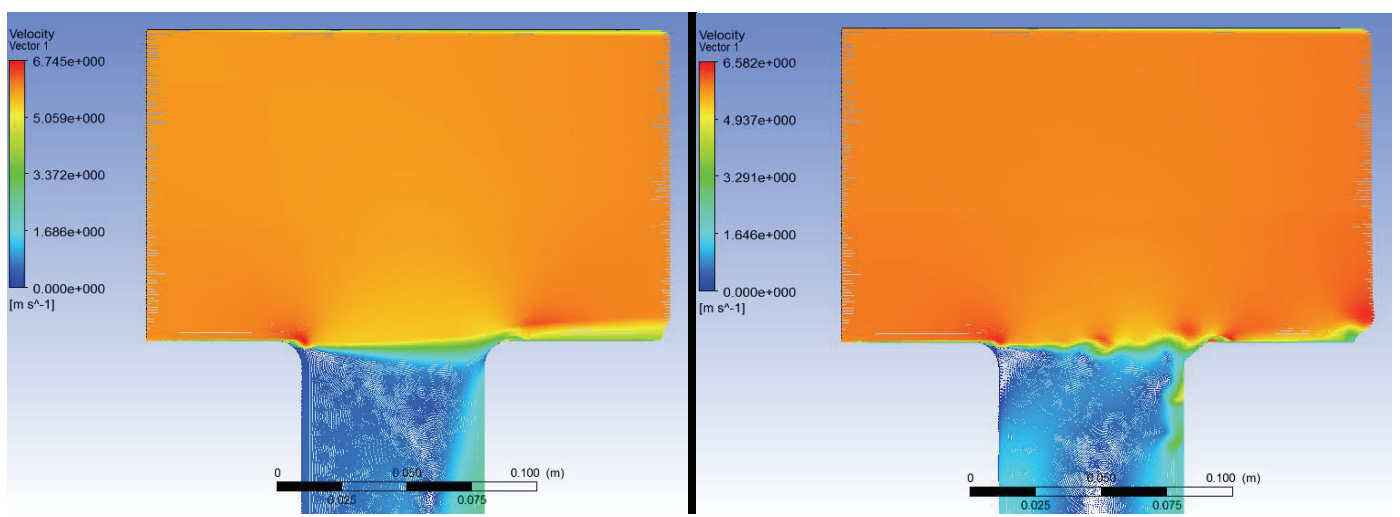

Fig. 3 - Calculation results with $k-\varepsilon$ model (left) and RSM model (right)

The most important part of the model is the redistribution term $\Phi_{\mathrm{ij}}$ responsible for balancing of correlations $\mathrm{u}_{1}^{\prime} \mathrm{u}_{\mathrm{j}}^{\prime}$. A detailed description can be found in [8].

The model RSM is applied in cases when eddy viscosity hypothesis doesn't hold and the calculation results could be inaccurate. The number of solved equations is higher (6 transport equations for Reynolds stresses components, transport equation for dissipation) and it leads to higher robustness and to a higher demand on calculation time. It is used when a non-isotropy flow is expected, in vortex flow, in cases of strong flow curvatures etc. Despite some disadvantages of the RSM model, it was the only possible choice for the given problem. Other commonly used models (k- $\varepsilon$, RNG, k$\omega)$ gave the wrong results. In fig. 3 left is an illustration of the flow field obtained with application of k- $\varepsilon$ model. Calculated flow field is steady, without periodic vortexes and this result doesn't agree with experience. It's clear that this type of problem, the choice of a turbulence model does matter. The boundary condition of the calculation was the total pressure at the input and static pressure at the output of the main pipe.

\section{RESULTS OF CALCULATIONS}

In fig. 4 a velocity field in the interface of the junction is shown. It is evident that on the rounded trailing edge, the stream detaches and as a series of vortexes travels to the leading edge. A wavy interface separates the stream with higher velocity in the main pipe and the region with low gas velocities in the side branch.

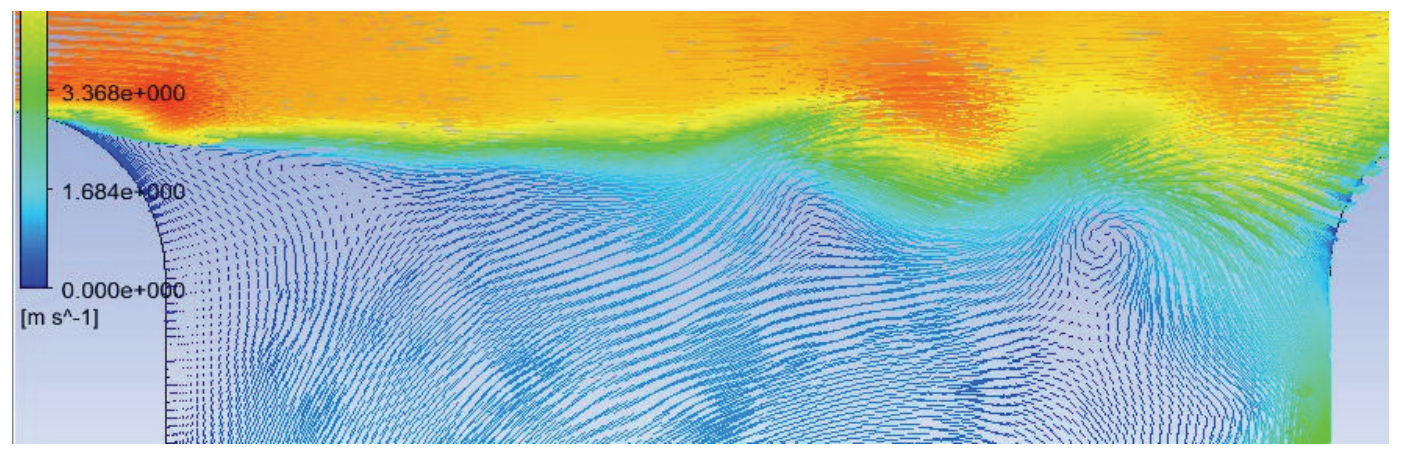

Fig. 4 - Velocity field in the interface of the junction 


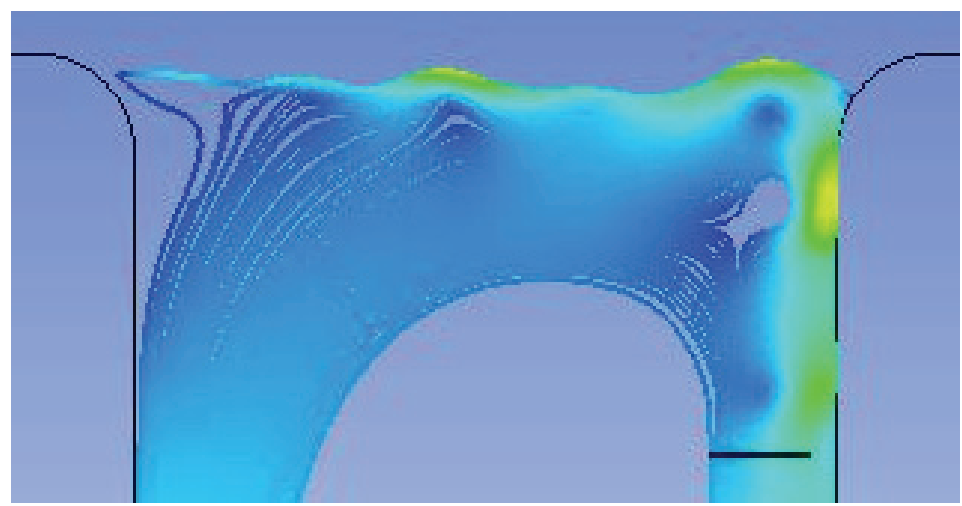

Fig. 5 - Streamlines in the closed side branch

Despite steady boundary conditions the flow in the junction is non-stationary and has a periodic character. Strokes of the stream on the leading edge induce pressure and velocity pulsations.

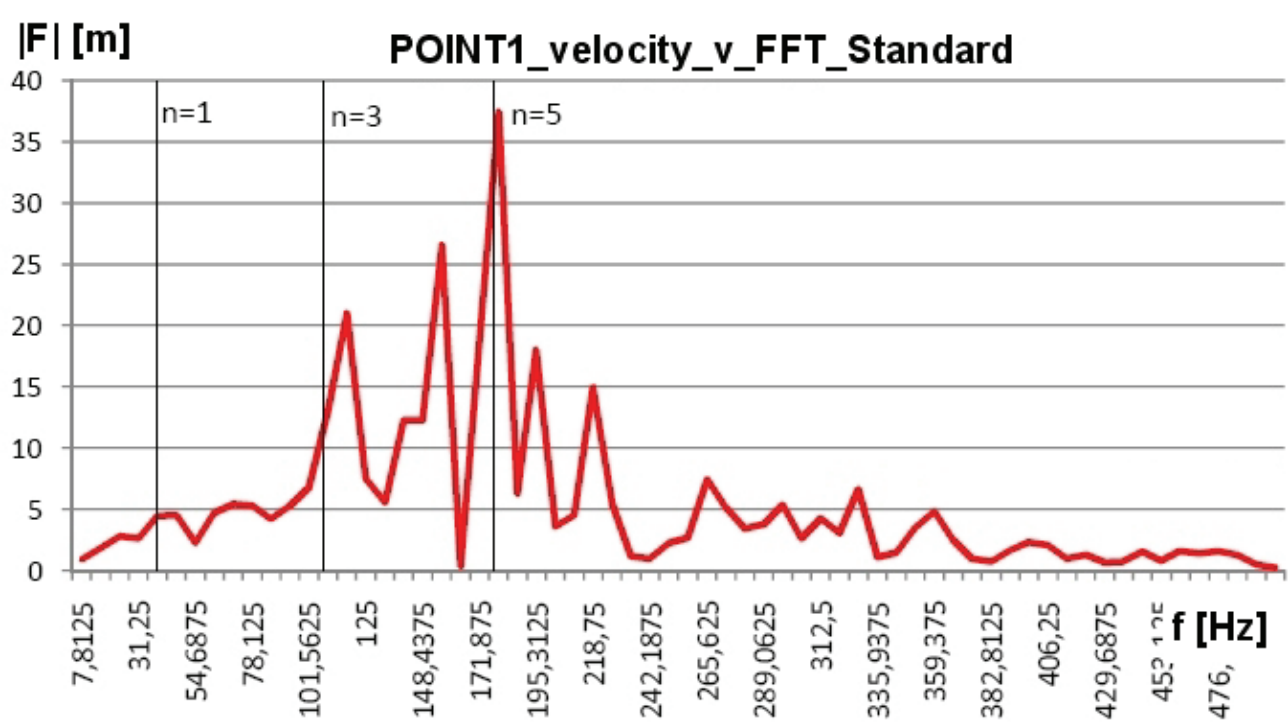

Fig. 6 - FFT analysis of the velocity course in Point P1 for edge radius $R 10$

It is interesting that there is almost no mixing between the fluid in the main pipe and the fluid in a closed branch. In fig. 5 the streamlines in the closed side branch are shown. This figure shows that in the branch a circulation flow along walls may be observed. 


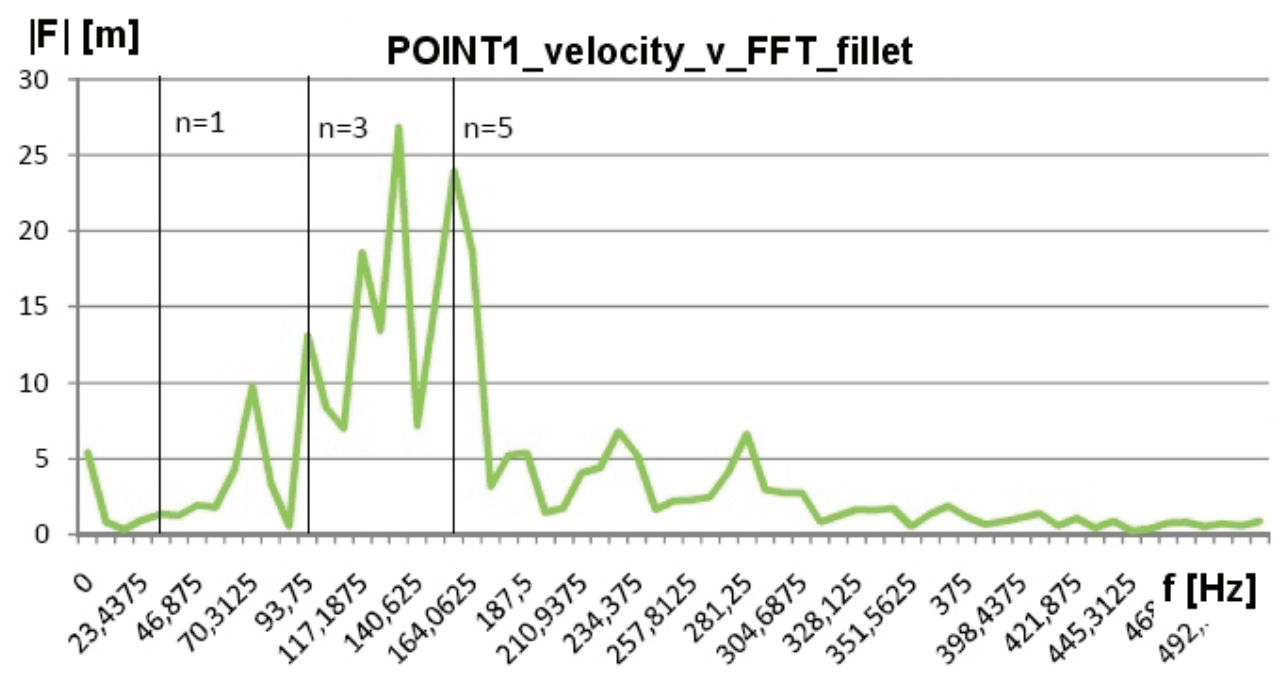

Fig. 7 - FFT analysis of the velocity course in Point P1 for edge radius $R 20$

Low velocities of the circulation flow in a closed branch are possible to neglect when analyzing the gas oscillations. Gas oscillations may be then assumed as one-dimensional. The exciting frequency is coincidental with the frequency of oscillating interface. The frequencies of exciting pulsations in the side branch were taken from points P1, P2 - fig. 3 and analyzed by applying the FFT algorithm. The question is, how does the calculated frequencies correspond with experiences or experimental data.

For the comparison of results of calculation with experimental data we utilized the results of paper [2], especially equation (3) - empirically estimated form Strouhal's number. From equations (1), (2) and (3) it is possible to estimate resonant frequencies for an arbitrary closed side branch of given geometrical (diameters D and d, length L, radius r) and flow (mean velocity, acoustic velocity) parameters.

Resonance occurs when the number $\mathrm{n}$ in equation (1) acquires an odd value. Frequencies for odd $n$ values are marked as vertical lines in comparisons shown in fig. 6 and fig. 7. These lines actually represent coincidence of the exciting frequency and an acoustic mode of gas in the closed branch. Fig. 6 illustrates the magnitude spectrum of the y-component of velocity at point P1 (see fig. 2) obtained by FFT analysis. The agreement between calculated frequencies in the spectrum and resonance frequencies obtained from experiment (lines $n=1, n=3$ and $n=5$ ) is surprising. Similar rates of agreement occurred in all tested cases (for different mean velocity in main pipe, and different edge radiuses). In fig. 7, the results of calculation with a different edge radius (R20) are presented. Frequencies of the spectrum are lower and it corresponds also with experimental results (vertical lines $n=1,3,5$ also moved to lower values).

\section{CONCLUSIONS}

The present work describes a method of CFD calculation of self-induced vibrations in the closed side branch. This paper presents the methodology (model of flow, turbulence model, meshing etc.) as well as some results. The results indicate that the calculation is significantly influenced by the incorporated turbulence model. On the basis of obtained results, it is possible to state, that the described method for solving (mesh, turbulence model, boundary conditions, 
SCIENTIFIC PROCEEDINGS 2011, Faculty of Mechanical Engineering, STU in Bratislava Vol. 19, 2011, pp. 119-125, DOI: 10.2478/v10228-011-0020-1

suggested simplifications) gives reliable predictions regarding the exciting frequencies in the closed branch. The calculation is usable for analysis of critical cases.

\section{REFERENCES}

[1] VARCHOLA M., KNÍŽAT B., TÓTH P.: Hydraulické riešenie potrubných systémov, Vienala Košice, 2004, ISBN 80-8073-126-8 Bratislava 2004

[2] JUNGOWSKI W. M., BOTROS K. K., STUDZINSKI W.: Cylindrical Side-branch as Tone Generator. Journal of Sound and Vibration, Vol. 131, Issue 2, 1989, p. 265-285

[3] TROJÁK M.: CFD simulácia Helmholtzovho rezonátora, Diplomová práca, SjF STU v Bratislave, 2011

[4] KNÍŽAT, B.-VARCHOLA M.: Prúdením indukované kmitanie potrubí. In: Aplikácia experimentálnych a numerických metód v mechanike tekutín a v energetike, str. 131-136. Žilina 2010, ISBN 978-80-554-0189-8.

[5] ZIADA S.-BÜHLMANN E. T.: Self-excited resonances of two side-branches in close proximity. Journal of Fluids and Structures, Volume 6, Issue 5, September 1992, Pages 583601

[6] MEISSNER M. W.- CZECHOWICZ M. R.: Experimental Investigation of Flow-Induced Acoustic Oscillations in a Piping System with Closed Branches, Applied Acoustics 45 (1995) 359-375

[7] GRAF H. R.- ZIADA S.: Excitation source of a side-branch shear layer, Journal of Sound and Vibration 329(2010) 2825-2842.

[8] ANSYS CFX, Reference Manual.

This work was supported by the Scientific Grant Agency VEGA under contract number 1/0215/11. 